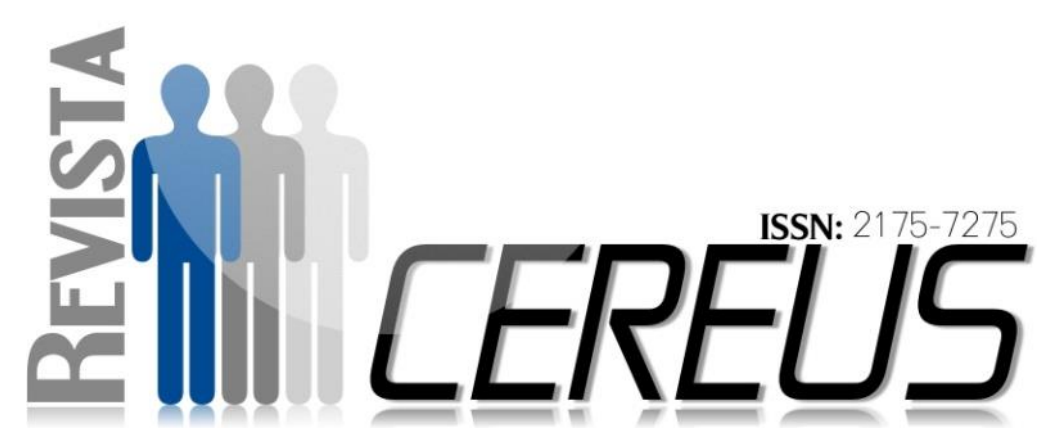

\title{
O PAPEL COGNITIVO DA MÚSICA NO PROCESSO DE ENSINO NA EDUCAÇÃO INFANTIL
}

\section{RESUMO}

PEREIRA, Evanilda ${ }^{1}$

COUTINHO, Francisca Jorge ${ }^{1}$

DA MOTA, Laide Bezerra ${ }^{1}$

PEREIRA, Bruno Gomes²

O presente artigo tem por finalidade perpetrar uma revisão na leitura sobre o papel cognitivo da música no processo de ensino e aprendizagem na Educação Infantil, observando a importância deste método na formação da criança através do lúdico, e investigando de que forma a música contribui no desenvolvimento físico, mental e afetivo, evidenciando que a música auxilia no desenrolar das diversas atividades pedagógicas propostas para a Educação Infantil. Abordar-se uma pesquisa de cunho bibliográfico contextualizando teorias relacionadas ao tema: "Música" no contexto educacional. A metodologia utilizada partiu de uma pesquisa bibliográfica, cuja fundamentação está embasada em teóricos renomados nesta área do conhecimento. Entende-se que uma educação

\footnotetext{
${ }^{1}$ Mestrando do programa em Ciências da Educação da FIAVEC, polo de Araguaína. ${ }^{2}$ Doutor em Letras pela UFT. Professor Adjunto do Centro Universitário ITPAC e docente do programa de Mestrado em Ciências da Educação da FIAVEC, polo de Araguaína. E-mail para correspondência: brunogomespereira_30@hotmail.com
} 
democrática pautada na valorização do ser humano, requer esforços variados para criar e consolidar ações objetivando o desenvolvimento do ser humanos.

Palavras chave: Cognição. Ludicidade. Intervenção.

\section{THE COGNITIVE ROLE OF MUSIC IN THE EDUCATION PROCESS IN EARLY CHILDHOOD EDUCATION ABSTRACT}

This article is intended to perpetrate a review on reading about the cognitive role of music in the process of teaching and learning in early childhood education, noting the importance of this method in the formation of the child through the playful, and investigating how the music helps in physical, mental and emotional, showing that music helps in the conduct of various pedagogical activities proposals for early childhood education. Address-if a search of bibliographical nature theme related theories context: "Music" in the educational context. The methodology departed from a bibliographical research, whose rationale is based on renowned theorists in this area of knowledge. It is understood that a democratic education based on the exploitation of human beings, requires a variety of efforts to create and consolidate actions aiming at the development of the human being.

Keywords: Cognition. Playfulness.Intervention 


\section{INTRODUÇÃO}

Quando nos referirmos ao uso da música no desenvolvimento da criança na educação infantil observamos diversidades de ferramentas e recursos que podem ser utilizado para auxiliar no processo de ensino da criança. Podemos ver isso nas diversas situações, como nos momentos de acolhida, hora do lanche, data comemorativas, nos momentos de relaxamento e nas atividades recreativas e físicas em geral. E não é diferente na vida das crianças em suas relações com o mundo no processo de aprendizagem fora do ambiente escolar, por que em casa ela também e utilizada, possibilitando a interação com os pais, avós e outras fontes como: televisão e rádio, que rodeiam o dia a dia das crianças, que vem formar um repertório inicial no seu universo sonoro. Brincando elas fazem demonstrações espontâneas, quando em família ou por intervenção do professor na escola, possibilitando a familiarização da criança com a música.

Em muitas situações do seu convívio social, elas vivem ou entram em contato com a música já no início no ventre materno e segue no decorrer da sua infância. O uso de música na infância datam desde a Grécia antiga (WEST, 2000). O próprio Platão descreveu, em sua obra intitulada "Leis", o processo no qual o pranto de um bebê é acalmado e transformado em sono através de uma canção de ninar, acompanhada pelo gesto materno do balanço. No decorrer da história diversos filósofos, médicos e educadores discutiram os efeitos sedativos e curativos da música em diversas populações e em diversos contextos, incluindo-se o primeiro ano de vida (WEST, 2000). Uma das características das canções infantis, sejam elas canções de ninar ou canções de brincar, é a simplicidade. Elas empregam intervalos melódicos pequenos, ritmos bastante simples e uma quantidade grande de repetições de frases musicais (Trehub, Unyk e Trainor, 1993a), sendo consideradas apropriadas para os bebês e crianças em geral. Além da finalidade, o que diferencia uma canção de ninar de uma canção de brincar é o andamento. Canções de brincar são geralmente mais rápidas, e apresentam jogos de palavras ou sugestões de movimentos corporais que auxiliam a percepção auditiva e o desenvolvimento da 
coordenação motora, da sociabilidade, da linguagem e da musicalidade do bebê.

Nas brincadeiras infantis, as crianças usam a música como forma de expressão e também para estabelecer regras, relações sociais, diversão, alegria e aprendizagem. Esses exemplos dão um breve panorama da importância da música na educação infantil, seja ela escolar ou na família, com tudo isto ver-se que é notória a importância de se trabalhar musicalização na educação infantil, pois ela contribui muito para 0 desenvolvimento tanto corporal, mental, linguístico entre outros. Ela favorece na percepção de pontos fortes e fracos da criança principalmente á capacidade de memória auditiva, observação, discriminação e reconhecimento dos sons, portanto torna- se relevante trabalhar com música dentro e fora da sala de aula.

\subsection{LUDICIDADE: A MÚSICA COMO} EXEMPLO

Quando o assunto é brincar não há o que se discutir, brincando também se aprende, a criança necessita desse recurso para poder assimilar o mundo a sua volta e assim fazer relações importantes com o mundo dos adultos. Quando uma criança brinca de boneca que representa o papel da mãe, por exemplo, ela não está apenas refletindo o seu cotidiano na família, mas está também colocando a sua ideia de como ela vê tudo o que ocorre ao seu redor. É nessa simples brincadeira que a criança vai expor suas alegrias, mágoas, percepções, subjetividades daquilo que ela vivencia. O uso da ludicidade é uma ferramenta que ajuda na assimilação de qualquer assunto que se queira que uma criança adquira.

Essa associação da música, enquanto atividade lúdica ligada a outros recursos dos quais dispõem o educador, facilita 0 processo de ensinoaprendizagem, pois incentiva a criatividade do educando através do amplo leque de possibilidades que a música disponibiliza. Para Chiarelli (2005), a música é importante para o desenvolvimento da inteligência da interação social da criança e a harmonia pessoal, facilitando a integração e a inclusão. Para ele a música é essencial na educação, como atividade mas também como instrumento de uso na interdisciplinaridade na educação. Aliar a música à educação também obriga o professor a assumir uma postura mais dinâmica e interativa diante do 
educando.

$\mathrm{Na}$ Educação infantil em si a música pode e deve ser inserida já na acolhida, ou seja, ao receber as crianças quando chega na sala, com som ambiente. Como também no momento devocional e cívico por meio de jogos ou brincadeiras de maneira que esta aprendizagem seja prazerosa à criança facilitando assim 0 interesse pelas brincadeiras musicais. Segundo PIRES (2008, p. 30): A brincadeira musical na Educação Infantil deve prever ações como: a escuta de músicas e a diferenciação de som e silêncio, a expressão corporal em diferentes ritmos musicais, o cantar diversas alturas e intensidades sonoras, a exploração dos sentimentos através da música e a criação musical livre e com regras. As atividades lúdicas de musicalização permitem que a criança conheça melhor a si mesma, desenvolvendo sua noção de esquema corporal, e também permitem a comunicação com o outro. A fonte de conhecimento da criança são as situações que ela tem oportunidade de experimentar em seu dia a dia. Assim, o processo de aprendizagem se torna mais fácil quando a tarefa escolar atende aos impulsos deste último para a exploração e descoberta, quando o tédio e a monotonia se tornarem ausentes das escolas, quando o professor, além das aulas expositivas e centralizadoras, possa propiciar experiências diversas com seus alunos, facilitando assim a aprendizagem. Ou seja, pensar as funções do ensino de música na educação infantil, nos leva ao cotidiano escolar e as práticas dos professores e seus alunos, de como a música aparece e suas particularidades, suas possibilidades e linguagens. Mas ainda é necessário refletir a respeito de novas possibilidades da música na educação infantil. Portanto, a integração entre os aspectos sensíveis, afetivos, estéticos e cognitivos, assim como a promoção de integração e comunicação social, conferem um caráter significativo à linguagem musical. Além disso, a música uma das mais importantes formas de expressão humana, o que por si só justifica sua presença no contexto da educação de um modo geral e, principalmente, na educação infantil particularmente.

Enquanto brinquedo, a música oferece um universo estruturado com significações originais, no qual a criança pode mergulhar. A criança não apenas imita, mas inventa, conversa, anula, transforma e dá novas significações (MAFFIOLETTI 2008, 
p.06)

Desta forma entendemos que a ludicidade e a música caminham lado a lado no ensino aprendizado das crianças da educação infantil. De acordo com Rocha (2000, p.66) "A atividade lúdica é assim, uma das formas pelas quais a criança se apropria do mundo, e pela qual o mundo humano penetra em seu processo de constituição enquanto sujeito histórico. Porém, o professor deve planejar suas atividades fundamentadas nas necessidades e nos interesses das crianças, sempre pensando na ampliação dos conhecimentos, das vivências e experiências delas; com o objetivo de ir além do que a criança pode aprender em casa, na comunidade, ou por meio das diferentes mídias.

Para que a musicalização se realize nas instituições de educação infantil, é necessário que o professor amplie seus conhecimentos referentes à música, como também reflita sobre sua prática pedagógica, pois, as atividades com a musicalização devem ser diárias, em diversos momentos e espaços da rotina escolar, como ao contar histórias, dramatizar, durante 0 momento de higiene, ao realizar atividades que envolvam movimento corporal, ao construir instrumentos musicais, manusear os instrumentos, ao dançar e cantar, no parque, nas refeições.

\subsection{COGNIÇÃO: CONTRIBUIÇÕES} PARA ENSINO

A música é uma linguagem que comunica sensações, sentidos e passa por organização de som e silêncio. Está presente nas mais diversas situações. A afetividade, a cognição e a estética são partes integrantes dela. Gonçalves (2009) afirma que a compreensão da música como linguagem e forma de conhecimento, leva-nos a ver a criança não como um ser estático e sim como alguém interagindo com 0 meio, organizando suas ideias e pensamentos.

Os primeiros anos de aprendizagem são propícios para que a criança comece a entender o que é linguagem musical, aprenda a ouvir sons e a reconhecer diferenças entre eles. Todo 0 trabalho a ser desenvolvido na educação infantil deve buscar a brincadeira musical, aproveitando que existe uma identificação natural da criança com a música. A atividade deve estar muito ligada à descoberta e à criatividade 
(GONÇALVES, 2009, p.9).

A música também pode ser usada na Educação Infantil em contribuição para 0 processo ensinoaprendizagem. Utilizando seus vários níveis de alcance desde a socialização até o gosto musical da criança. A música vem ainda contribuir para a formação do individuo como todo. Por meio da música, a criança entrará em contato com o mundo letrado e lúdico. Observa-se sua importância com 0 valioso instrumento, o qual deverá ser trabalhado e estimulado provocando no educando possibilidades de criar, aprender e expor suas potencialidades (GONÇALVES, 2009, p.6).

\subsection{DIMENSÃO COGNITIVISTA DE "GRAMÁTICA"}

À luz dos pressupostos gerais da Linguística Cognitiva, os fenômenos linguísticos são objeto de estudo cujo ponto de partida se vale da noção de que a há uma inter-relação entre a linguagem e as distintas semioses ou ações cognitivas, originadas nas interações humanas. Na linguagem, a construção dos significados é mediada pela cognição e, como aponta Ferrari
(2011, p. 14), o "significado deixa de ser um reflexo direto do mundo, e passa a ser visto como uma construção cognitiva através da qual o mundo é apreendido e experiência". A questão apontada acima por Ferrari destaca a relevância de se estabelecer uma correlação entre "significado" e "experiência", sabendo então que o significado em si e por completo não existe na construção de forma homogênea e à parte do contexto.

A perspectiva baseada no uso é adota pela Linguística Cognitiva, tendo como paradigma de análise a ideia de que o significado das construções é orientado pelas experiências concretas do falante e pelo contexto. Quando se trata do estudo e da observação do uso real da língua, as construções são entidades não autônomas e, portanto, heterogêneas e de pareamento "formasignificado" diverso (GOLDBERG, 1995) cuja pesquisa abarca a ideia de que "não existe linguagem humana independentemente do contexto sociocultural" (SILVA, 2004, p. 7), situado e definido. Para Salomão (1999, p. 71), essa ênfase do uso real põe em foco a questão de que "fazer sentido (ou interpretar) é necessariamente uma operação social na medida em que o sujeito nunca 
constrói o sentido-em-si, mas sempre para alguém (ainda que este alguém seja si mesmo)". De acordo com a autora, o sujeito produz a significação atuando na cena concreta, "investindoa de sentido, seja com base em conhecimento consensual, disponível como norma de conduta, ou por conta da motivação singular de realizar objetivos localmente relevantes" (SALOMÃO, 1999, p. 71).

Assumida a perspectiva de que 0 significado da estrutura linguística é realizado pelos participantes de maneira interativa, postula-se que as orações condicionais informam sobre 0 mundo $e$ as coisas de modos particulares e, por isso, estão além de representarem padrões sintáticos bemformados nas línguas naturais. Considerando a linguagem não como sistema autônomo, desarticulado da experiência humana, Salomão (1999, p. 71) afirma que as unidades linguísticas devem ser vistas a partir da noção de interatividade, como revela o trecho destacado:

Fazer sentido (ou interpretar) é

\section{METODOLOGIA}

As classes e as construções da gramática são entidades simbólicas e, necessariamente uma operação social na medida em que o sujeito nunca constrói o sentido-em-si, mas sempre para alguém (ainda que este alguém seja si mesmo). Construir sentido implica em assumir determinada perspectiva sobre uma cena, perspectiva que é também mutável no próprio curso da encenação.

$\mathrm{Na}$ opinião da autora, as construções gramaticais adquirem 0 status de manifestar os papeis sociais e não os sentidos em si. A constituição de unidades simbólicas é resultado da ação e da interferência dos sujeitos, "seja com base em conhecimento consensualizado (o $\mathrm{MCl}$ da interação), disponível como norma de conduta, ou por conta da motivação singular de realizar objetivos localmente relevantes" (SALOMÃO, 1999, p. 71). Fundamentadas nos pressupostos gerais da Linguística Cognitiva (LANGACKER, 1991; GOLDBERG, 1995; FERRARI, 2011), algumas particularidades sobre a gramática são destacadas.

portanto, significativas, sendo propriedades sintáticas motivadas, na 
experiência e no cotidiano, por aspectos semântico-pragmáticos, por modelos cognitivos contínuos e por modelos socioculturais diversos (LANGACKER, 1991; FILLMORE, 1988; GOLDBERG, 1995). Assim, cada construção sintática reflete processos cognitivos, motivados pela experiência, conhecimentos coletivos e intenções/papeis sociais no foco da interação.

A exemplo dessa abordagem, o estudo das construções condicionais na interação jurídica desenvolvido por Roxo (2006)3 é uma análise baseada na hipótese de que a condicionalidade não deve ser definida como uma categoria lógica, de modo que se possa atribuir um valor de verdade aos conteúdos de p e q na sentença. Assim, a configuração sintática "Se V. PRES. IND, V. PRES. IND" carrega informações semânticas e distintas relações pragmáticas nas cenas comunicativas do caso julgado. Quando é dita pelo promotor, configurase o mesmo alinhamento do Ministério Público quanto à defesa dos princípios da vida na sociedade como em: Promotor: Se nem o Estado tem legitimidade para tirá-lo ninguém mais tem. Ninguém tem o direito de antecipar a morte de uma outra pessoa.
Quando é dita pelo defensor, o ponto de vista advém particularmente da atenção do próprio falante quanto à realização dos fatos do caso concreto. Pragmaticamente, instaura-se outro ponto de vista, diferente do promotor, a favor do réu: Defensor: Se é com Godir deve ser com qualquer um, pra mim, pros senhores, pra qualquer uma dessas pessoas. No interrogatório, ao ser interpelado pelo juiz, a configuração sintática "Se V. PRES. IND, V. PRES. IND" sinaliza uma conclusão que beneficia o próprio falante, o réu. $A$ construção condicional abaixo é um exemplo deste pareamento: Réu: Se o nome dele é Daniel, eu conheço ele de vista. Essa configuração sinaliza que o estado de coisa na prótese "Se o nome dele é Daniel" expressa uma conclusão "Eu conheço ele de vista", alinhada ao próprio conhecimento do estudo desenvolvido na tese de doutorado intitulada Aspectos cognitivos das construções condicionais em audiências públicas, defendida em 29 de agosto de 2006, sob a orientação da Prof. a Dra Lílian Vieira Ferrari (Depto de Linguística, UFRJ). Baseado no estudo desenvolvido por Sweetser (1990), a pesquisa mostra que o funcionamento da condicionalidade se refere a domínios cognitivos distintos, podendo 
se referir a situações do mundo real (condicionais de conteúdo ou condicionais preditivas), a processos de raciocínio (condicionais epistêmicas) e a processos de atos de fala (condicionais pragmáticas) de acordo com a perspectiva do falante sobre a situação ou estado de coisa representado na cena comunicativa.

\section{SUGESTÕES DE INTERVENÇÃO PEDAGÓGICA ATRAVÉS DA MÚSICA: PROPOSTA DE CRIAÇÃO DE UMA METODOLOGIA}

Há muitas possibilidades de trabalhar os elementos musicais, como por exemplo: a exploração do conceito de som e silêncio - com brincadeiras de estátua; produção de vários tipos de sons com o corpo - arrastando os pés, batendo as mãos nas diferentes partes do corpo, etc.; estímulo ao desenvolvimento da linguagem falada por meio de canções; incentivo à composição pelas crianças de uma melodia- a partir de uma letra criada pelo grupo; incentivo à criatividade, concentração e memória pela imitação de sons criados pelos colegas; a utilização de brinquedos de diferentes texturas, formas e tamanhos que produzam sons diferentes: estímulos auditivos, visuais e motores; movimentos rítmicos, explorando todo o esquema corporal e acompanhamento das músicas com palmas ou percutindo algum objeto ao pulso da melodia; trabalho da percepção da pulsação com movimentos corporais com os braços, mãos, pernas, pés, cabeça e tronco. Em qualquer ambiente que a criança esteja exposta deverá ser estimulada a prestar atenção aos sons que com certeza estão acontecendo e se possível identificá-los relacionando-os e nomeando-os. (Gonçalves, 2009, p.7). É o cérebro que interpreta as ondas sonoras recebidas pelo ouvido.

Assim como todos os sentidos externos do corpo humano (audição, olfato, tato, paladar e visão) a audição é resultado de uma interpretação cerebral. Quanto mais rica for uma música em seus diferentes sons (agudos, médios e graves), timbres (cordas, sopro e percussão), ritmos (pulsações), velocidades (notas longas, médias e curtas), intensidade (forte, média e fraca) com harmonia (combinação de sons simultâneos), 
mais o cérebro de quem a ouve será estimulado.

Recomenda-se às crianças em idades iniciais do desenvolvimento cerebral (0 a 6 anos) ouvir músicas eruditas, a exemplo das "clássicas", por serem ricas em expressões sonoras propícias ao desenvolvimento da acuidade cerebral auditiva, característica esta que é de grande importância para 0 aprendizado de

\section{CONSIDERAÇÕES FINAIS}

Entende-se que o professor necessita ter habilidades e conhecimentos teóricos para perceber e intervir em situações que envolvam conflitos e crises emocionais deve-se ter consciência do poder do contágio emocional entre as crianças e atuar nessas situações, promovendo intervenções que possam ser administradas de forma significativa e, possivelmente, benéfica para o grupo.

Há uma necessidade de renovação dos processos de ensinoaprendizagem que devem levar em conta a renovação também das estruturas organizacionais. Essa renovação deve ser pautada nos direitos humanos, e contemplar temas idiomas. A arte de combinar os sons, é uma excelente fonte de trabalho escolar porque, além de ser utilizada como terapia psíquica para o desenvolvimento cognitivo, é uma forma de transmitir ideias $\mathrm{e}$ informações.

como estilo de direção, comunicação, sistema de relações, tratamento dos conflitos, avaliação institucional, normas disciplinares. É necessário construir estratégias que gere, tanto na sala de aula como na escola, um clima de segurança, confiança e respeito à individualidade de cada indivíduo que, por consequência, trará liberdade de expressão emocional, física e criativa.

$\begin{array}{rcll}\text { Deve } & \text { ser } & \text { questionada } & \text { a } \\ \text { separação } & \text { entre } & \text { racionalidade } & \text { e } \\ \text { afetividade, } & \text { e } & \text { valorizado } & \text { os }\end{array}$
sentimentos que estão presentes em todas as relações humanas. A razão não nega a emoção. A educação escolar tem que estar preparada para 
desenvolver a construção equilibrada da personalidade como um todo.

Aprender a conviver em sociedade é um dos objetivos da educação escolar. Para isso, é necessário ensinar a conciliar a relação igualdade e diferença, paz e violência, aceitação e preconceito, sendo que esse processo exigirá dos professores uma postura democrática e não autoritária onde trabalha a criatividade e liberdade de expressão, que são contrários ao modelo atual onde é esperado o mesmo comportamento para todos, como se fosse possível colocar uniformes no interior dos alunos. Até mesmo o modelo de avaliação da aprendizagem deve ser revisto, pois não aprendemos da mesma forma e não nos comunicamos no mesmo nível de linguagem, o que não quer dizer que não somos capazes de aprender, mas sim que todo ser humano é único.

Diante do que foi exposto, evidencia-se a presença contínua da afetividade nas interações sociais, além da sua influência também contínua nos processos de desenvolvimento cognitivo. Nesse sentido, pode-se pressupor que as interações que ocorrem no contexto escolar também são marcadas pela afetividade em todos os seus aspectos. Pode-se supor, também, que a afetividade se constitui como um fator de grande importância na determinação da natureza das relações que se estabelecem entre os sujeitos (aluno) e os diversos objetos de conhecimento (áreas e conteúdos escolares), bem como na disposição dos alunos diante das atividades propostas e desenvolvidas.

\section{REFERÊNCIAS}

ALMEIDA, Maria Lúcia Leitão de. Cruzamento vocabular no português: aspectos semântico cognitivos. In: MIRANDA, Neusa Salim; NAME, Maria Cristina (Orgs.). Linguística e cognição. Juiz de Fora, MG: UFJF, 2005.

ALMEIDA, Maria Lucia Leitão de; FERREIRA, Rosângela Gomes; PINHEIRO, Diogo et ali. Breve introdução à Linguística Cognitiva. In: ALMEIDA, Maria Lucia Leitão de: FERREIRA, Rosângela Gomes; PINHEIRO, Diogo et ali (Orgs.). Linguística cognitiva em foco: morfologia e semântica do português. Rio de Janeiro: Publit Soluções Editoriais, 2009.

CROFT, William. Syntactic argumentation and radical construction grammar. Radical construction grammar. Oxford,UK, 2001. 
FERRARI, Lilian Vieira. Introdução à Linguística Cognitiva. São Paulo: Contexto, 2011.

Construções gramaticais e a gramática das construções condicionais. Scripta, Revista do Programa de Pós-Graduação em Letras do Centro de Estudos Luso-afro-brasileiros da PUC Minas. Linguística e Filologia. Belo Horizonte: PUC Minas, v. 5, n. 9, 2001, pp. 143- 150.

FERRARI, Lilian Vieira. Os parâmetros básicos da condicionalidade na visão cognitivista. Veredas: Revista de Estudos Linguísticos. Juiz de Fora, MG: EDUFJF, v. 4, n. 1, jan.-jun. 2000, pp. 21-30.

GEERAERTS, D. Cognitive linguistics: basic readings. Berlin; New York: Mouton de Gruyter, 2006.

GERALDI, João Wanderley. Portos de passagem. São Paulo: Martins Fontes, 1993.

GODOI, Luís Rodrigo. A importância da música na Educação Infantil. Trabalho de Conclusão de Curso (Graduação em Pedagogia). Universidade Estadual de Londrina. Londrina, 2011.

GOLDBERG, Adele. Constructions: a construction grammar approach to argument structure. Chicago: University Press, 1995.

ILARI, Beatriz Senoi. Bebês também entendem de música: a percepção e a cognição musical no primeiro ano de vida. Disponível em: http://www.abemeducacaomusical.com.br/revistas/revistaabem/index.php/revistaabe $\mathrm{m} /$ article/view/435.2017.

MACEDO, Ana Cristina Pelosi de. Cognição e Linguística. MACEDO, Ana Cristina Pelosi de; FELTES, Heloisa Pedroso de Moraes e Farias, PEIXOTO, Emília Maria (Orgs.). Cognição e Linguística: explorando territórios, mapeamentos e percursos. Caxias do Sul, RS: EDUCS; Porto Alegre: EDIPUCRS, 2008.

MIRANDA, Neusa Salim. Domínios conceptuais e projeções entre domínios: uma introdução ao Modelo dos Espaços Mentais. Veredas: Revista de Estudos Linguísticos, Juiz de Fora, EDUFJF, v. 3, n. 1, jan.-jun. 1999.

UFJF, 2005.

; NAME, Maria Cristina (Orgs.). Linguística e Cognição. Juiz de Fora, MG: Ed.

NEVES, Maria Helena de Moura. A gramática de usos é uma gramática funcional. Alfa, São Paulo, 41(n. esp.), 1997. ROXO, Maria do Rosário. Aspectos cognitivos das construções condicionais em audiências públicas. Tese de doutorado. Universidade Federal do Rio de Janeiro, Rio de Janeiro, 2006.

NOGUEIRA, M.A. A música e o desenvolvimento da criança. Revista da UFG, Vol. 5, No. 2, dez 2003. Disponível em: Acesso em: 10 de Setembro 2011. 
PIRES, Gisele Brandelero Camargo. Lúdico e Musicalização na Educação Infantil. Centro Universitário Leonardo da Vinci. Indaial: Ed. Grupo UNIASSELVI, 2008.

WEST, Martin. Music therapy in antiquity. In: HORDEN, Penelope. Músicas medicine. Brookfield: Ashgate, 2000. p. 51-68.

Recebido em: 12/04/2017

Aprovado em: 09/08/2017 